\title{
Aqueous Medium Synthesis Route for Randomly Stacked Molybdenum Disulfide
}

\author{
Pravas Kumar Panigrahi and Amita Pathak \\ Department of Chemistry, Indian Institute of Technology, Kharagpur, West Bengal 721302, India \\ Correspondence should be addressed to Amita Pathak; ami@chem.iitkgp.ernet.in
}

Received 23 October 2012; Revised 6 February 2013; Accepted 20 March 2013

Academic Editor: Dongsheng Wen

Copyright ( 2013 P. K. Panigrahi and A. Pathak. This is an open access article distributed under the Creative Commons Attribution License, which permits unrestricted use, distribution, and reproduction in any medium, provided the original work is properly cited.

\begin{abstract}
Synthesis of poorly crystalline, randomly oriented rag-like structures of molybdenum disulfide has been reported starting from aqueous solutions of ammonium molybdate, and thioacetamide in presence of sodium dodecyl sulfate via calcination of the amorphous precipitates, obtained through acidification of the in situ generated intermediate of ammonium tetrathiomolybdate. $\mathrm{X}$-ray photoelectron spectroscopy, UV-visible spectroscopy, and X-ray diffraction of the calcined samples reveal the formation of single-phase $\mathrm{MoS}_{2}$, while the amorphous precipitates have been found to be a mixture of $\mathrm{Mo}_{2} \mathrm{~S}_{5}, \mathrm{MoS}_{3}$, and a trace amount of $\mathrm{H}_{2} \mathrm{MoS}_{4}$. Highly folded and disordered layers of rag-like $\mathrm{MoS}_{2}$ have been confirmed through high-resolution transmission electron microscopy. The electrical conductivity for the cold pressed pellet of the $\mathrm{MoS}_{2}$ sample is found to be significantly higher than that of $2 \mathrm{H}-\mathrm{MoS}_{2}$ and increases further on annealing.
\end{abstract}

\section{Introduction}

Molybdenum disulfide $\left(\mathrm{MoS}_{2}\right)$ is a hexagonal layer structured material. The $\mathrm{MoS}_{2}$ layers, each of which consists of a layer of molybdenum atoms sandwiched between two layers of sulfur atoms, are connected by weak van der Waals force. Due to the weak interactions between the sheets of sulfur atoms, $\mathrm{MoS}_{2}$ exhibits excellent lubrication property $[1,2]$. It also finds applications as electrode in high-density lithium batteries [3], solar cells [4] in form of thin films, and as intercalation host to produce new materials $[5,6]$. From a catalytic point of view, $\mathrm{MoS}_{2}$ possesses outstanding properties towards methanation of $\mathrm{CO}$ with hydrogen [7] and hydrodesulfurization reaction for removal of sulfur compounds from crude oil $[8,9]$. It has been found that the catalytic activity of $\mathrm{MoS}_{2}$ strongly depends on the number of coordinatively unsaturated sites [10]. Thus, the catalytic activity of $\mathrm{MoS}_{2}$ is influenced by the particle size as well as the number of layers, demonstrating that the morphology is also an important parameter for such applications.

Till date, $\mathrm{MoS}_{2}$ powders with different morphologies have been synthesized through a wide range of methods, such as thermal decomposition of ammonium tetrathiomolybdate or amorphous $\mathrm{MoS}_{3}[11,12]$, reaction of stoichiometrically mixed molybdenum and sulfur powders in vacuum at high temperature [13], and gas-phase reactions of molybdenum oxides with $\mathrm{H}_{2} \mathrm{~S}$ under reducing atmosphere $[14,15]$. There are also reports on the use of other high-energy sources like laser [16], electron beam [17], and $\gamma$-radiation [18] for the synthesis of nanotubes, fullerene-like, and other curved nanostructures of $\mathrm{MoS}_{2}$. As an alternative to these methods, which require high temperatures/pressures and/or sophisticated instrumentations, solution-based synthesis routes have been developed [19-21] and have gained popularity due to their simplicity and convenience. For example, hydrother$\mathrm{mal} /$ solvothermal processes have been carried out at different temperatures $\left(100-300^{\circ} \mathrm{C}\right)$ and incubation periods $(12 \mathrm{~h}-3$ days) by various research groups [22-25] to obtain fine powders of $\mathrm{MoS}_{2}$ with a variety of crystallinity. Among these reports, Li et al. [23] observed $\mathrm{MoS}_{2}$ nanoparticles with short range stacking of layers, when a solution containing $\left(\mathrm{NH}_{4}\right)_{2} \mathrm{Mo}_{3} \mathrm{~S}_{13}$ and hydrazine was treated hydrothermally at $180^{\circ} \mathrm{C}$ for $16 \mathrm{~h}$. Sonochemical method [26] has also been explored to produce $\mathrm{MoS}_{2}$. Alternatively, Bezverkhy et al. [27] have synthesized highly dispersed $\mathrm{MoS}_{2}$ by using $\left(\mathrm{NH}_{4}\right)_{2} \mathrm{MoS}_{4}$ and $\mathrm{N}_{2} \mathrm{H}_{4} \cdot \mathrm{H}_{2} \mathrm{O}$ via aqueous medium 
precipitation method. The same group has also reported the formation of single layered $\mathrm{MoS}_{2}$ with short fringes, when processed in presence of an organic surfactant in the reaction mixture [28]. Similarly, $\mathrm{Hu}$ et al. [29] have prepared the ball-like $\mathrm{MoS}_{2}$ nanoparticles on calcining the amorphous molybdenum sulfide $\left(\mathrm{MoS}_{x}\right)$, obtained through precipitation from the solution of $\mathrm{Na}_{2} \mathrm{MoO}_{4}$ and thioacetamide in water and alcohol. Recently, Wu et al. [30] have reported the preparation of poorly crystalline $\mathrm{MoS}_{2}$ nanospheres through calcination of $\mathrm{MoS}_{3}$ precursor obtained through precipitation in an aqueous medium in presence of polyethylene glycol.

Considering the technical simplicity and versatility of the precipitation synthesis approaches, we have described here an aqueous solution-based precipitation route for the preparation of poorly crystalline $\mathrm{MoS}_{2}$ with randomly stacked layers using commonly available starting reagents. Unlike most of the previous reports, the composition of the precursor powders has been studied by XRD, XPS, and thermal analysis. The present paper also includes the optical and electrical studies of the calcined powders, which have not been widely reported for the poorly crystalline $\mathrm{MoS}_{2}$ nanostructures, prepared and studied so far in the literature.

\section{Experimental}

2.1. Synthesis. The preparation of $\mathrm{MoS}_{2}$ was carried out through modification of the method described in literature [31]. All the chemicals were purchased and used as received. To start, $30 \mathrm{~mL}$ of $0.008 \mathrm{M}$ ammonium molybdate $\left(\left(\mathrm{NH}_{4}\right)_{6} \mathrm{Mo}_{7} \mathrm{O}_{24} \cdot 4 \mathrm{H}_{2} \mathrm{O}\right.$, Merck India, 98\%) solution was taken, and sodium dodecyl sulfate (SDS) of 10 times of $\mathrm{cmc}$ (critical micelle concentration) was added to it under constant stirring to obtain a clear solution. Then, $9.60 \mathrm{~mL}$ of $0.23 \mathrm{M}$ sodium dithionite $\left(\mathrm{Na}_{2} \mathrm{~S}_{2} \mathrm{O}_{4}, \mathrm{BDH}\right.$, England, 98\% pure) solution and $45 \mathrm{~mL}$ of $0.20 \mathrm{M}$ thioacetamide $\left(\mathrm{CH}_{3} \mathrm{CSNH}_{2}\right.$, Spectrochem India, 99\%) solution were added into the former solution and were thoroughly mixed together by stirring. The solution mixture was heated $\left(\sim 90^{\circ} \mathrm{C}\right)$ over a water bath to obtain a clear reddish yellow color solution. Acidification of this solution with concentrated $\mathrm{HCl}(\mathrm{pH}<1)$ led to a dark brown colored precipitate. The precipitate was isolated using a centrifuge and was washed with water for several times. Drying of the precipitate gave rise to brownish black powders, which were calcined at $400^{\circ} \mathrm{C}$ for $2 \mathrm{~h}$ under argon atmosphere to obtain the black powders of $\mathrm{MoS}_{2}$.

2.2. Characterization. The optical absorption spectrum of the reddish yellow colored solution of the intermediate as well as the ethanol dispersion of the calcined powders were studied at room temperature using Shimadzu UV-1601 UV-visible spectrophotometer. The phase and structure analyses of the virgin and the calcined powders were carried out on X'pert Pro 3040/60 high-resolution X-ray diffractometer using Cu $\mathrm{K} \alpha$ radiation $(\lambda=1.5418 \AA \dot{\AA})$. X-ray photoelectron spectra (XPS), using VG Microtech ESCA2000 Multilab apparatus, was obtained for the virgin and the calcined powders for determining the oxidation states of Mo and $\mathrm{S}$ in the respective

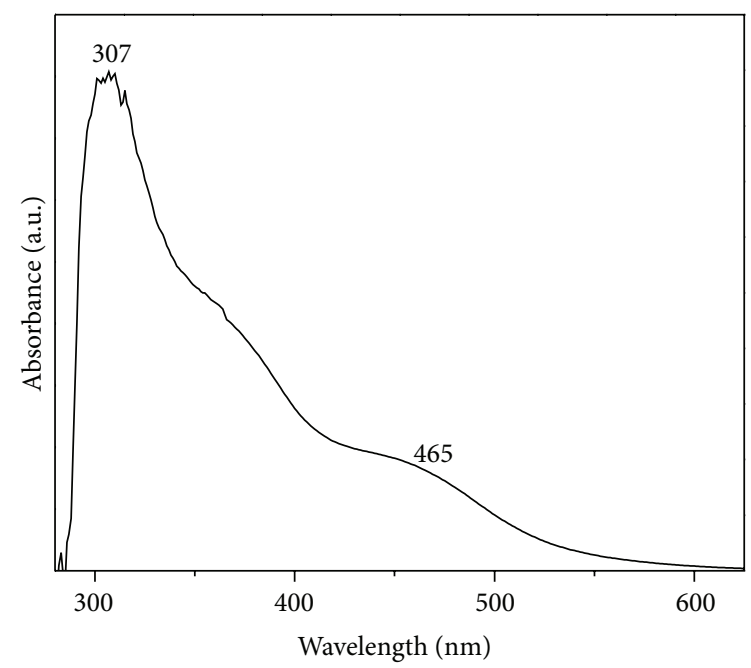

FIGURE 1: Optical absorption spectrum of the precursor solution containing $\mathrm{MoS}_{4}{ }^{2-}$ ions.

samples. Thermal analysis of the dried precipitate was performed at the heating rate of $6^{\circ} \mathrm{C}$ per min under dynamic argon using Perkin-Elmer Pyris Diamond TG/Differential thermal analyzer and alumina as the reference. Transmission electron microscope of model JEOL2010 (UHR) was used to study the microstructure of the calcined powders. The FTIR spectrum of the precursor sample was taken on a Perkin Elmer Fourier transform analyzer (FTIR spectrometer RXI). Electrical conductivity measurement was carried out on pressed pellet of the as-prepared calcined powders of $\mathrm{MoS}_{2}$ using a computer-controlled HIOKI LCR HITESTER at an AC signal of $1.0 \mathrm{~V}$. The surfaces of the pellets were coated with silver paint for electrical contact. Finally, the electrical connection of the pellet to the apparatus was made through nickel electrode and put in a temperature controlled furnace. The hydrodynamic size of the synthesized $\mathrm{MoS}_{2}$ sample was measured by using 90 Plus Particle Size Analyzer (made by Brookhaven Instruments). The BET (BrunauerEmmett-Teller) specific surface area of the calcined sample was measured through nitrogen adsorption isotherms at $77 \mathrm{~K}$ by using Quantachrome Instruments (Autosorb-1, Model no. ASI-C-9).

\section{Results and Discussions}

3.1. Analysis of the Precursor Precipitate. To understand the chemistry involved in the formation of precursor precipitate, the composition of the reddish yellow colored precursor solution obtained on heating the solution mixture over a water bath was characterized by UV-visible spectroscopy (Figure 1). This optical absorption spectrum shows two absorption peaks centered at $\sim 307$ and $465 \mathrm{~nm}$ corresponding to the tetrathiomolybdate ions $\left(\mathrm{MoS}_{4}{ }^{2-}\right)[32,33]$. These ions possibly get formed as an intermediate on heating the solution of heptamolybdate $\left(\mathrm{Mo}_{7} \mathrm{O}_{24}{ }^{6-}\right)$ and thioacetamide through 


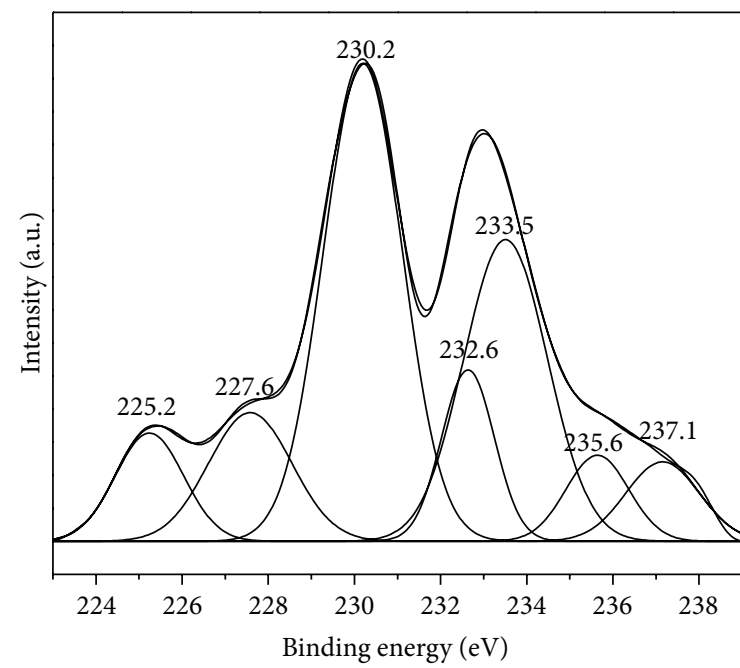

(a)

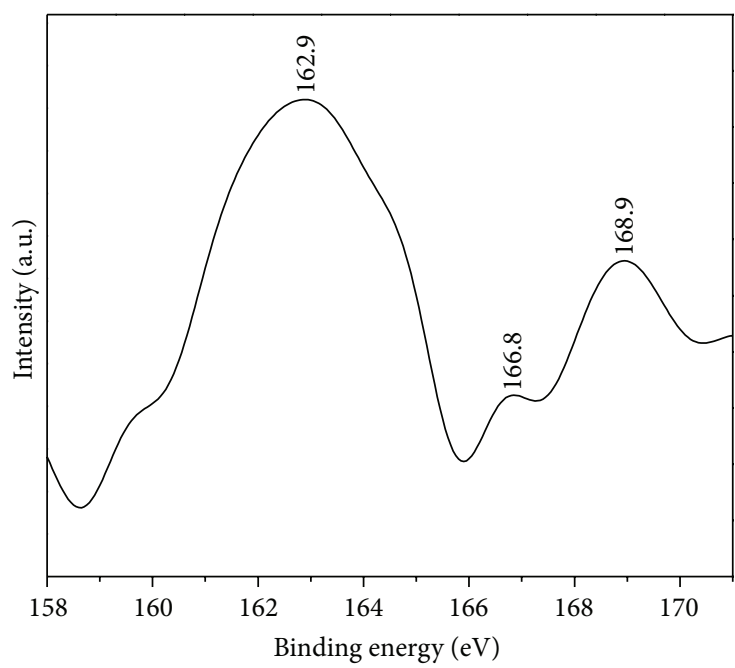

(b)

FIGURE 2: XPS spectra (a) for Mo, after and before curve peak fitting, and (b) for S in the as-precipitated precursor sample obtained after acidification of ATM solution.

exchange of oxygen atoms in molybdate ions by sulfur. The possible reaction involved can be written as follows:

$$
\begin{aligned}
& \mathrm{Mo}_{7} \mathrm{O}_{24}{ }^{6-}+28 \mathrm{CH}_{3} \mathrm{CSNH}_{2}+4 \mathrm{H}_{2} \mathrm{O} \\
& \longrightarrow 7 \mathrm{MoS}_{4}{ }^{2-}+8 \mathrm{H}^{+}+28 \mathrm{CH}_{3} \mathrm{CONH}_{2}
\end{aligned}
$$

Acidification of the solution containing tetrathiomolybdate ions with concentrated $\mathrm{HCl}$ led to brownish black colored precipitate of the sulfides. The composition of this as-precipitated precursor was investigated through analyzing the oxidation states of Mo and S in the samples by $\mathrm{X}$ ray photoelectron spectroscopy. The survey spectra (not shown) showed the peaks for carbon, an impurity in the vacuum system, and oxygen in addition to the elements of interest (i.e., Mo and S). The deconvoluted and curve-fitted spectra shown in Figure 2(a) corroborated to seven peaks centered at 225.2, 227.6, 230.2, 232.6, 233.5, 235.6, and $237.1 \mathrm{eV}$ corresponding to Mo and S species present in the sample. The peak at $227.6 \mathrm{eV}$ may be attributed to the $2 \mathrm{~s}$ binding energy of $S$ in elemental state [34]. The peak around $225.2 \mathrm{eV}$, which has a lower shift of $2.4 \mathrm{eV}$ with respect to $2 \mathrm{~s}$ binding energy of free $S$, originates from the sulfur bonded to Mo. The rest of the peaks can readily be fitted into three groups, 230.2 and $233.5 \mathrm{eV}, 232.6$ and $235.6 \mathrm{eV}, 233.5$ and $237.1 \mathrm{eV}$, representing the $3 \mathrm{~d}$ doublets, $3 \mathrm{~d}_{5 / 2}$ and $3 \mathrm{~d}_{3 / 2}$, respectively, of various oxidation states of Mo.

It is reported that, for any oxidation state of Mo, the $3 \mathrm{~d}$ doublet (i.e., $3 \mathrm{~d}_{5 / 2}$ and $3 \mathrm{~d}_{3 / 2}$ ) has an energy separation of $\sim 3.1 \mathrm{eV}$ and a characteristic $3 \mathrm{~d}_{5 / 2}: 3 \mathrm{~d}_{3 / 2}$ peak intensity ratio of $3: 2$ [35]. Furthermore, the $3 \mathrm{~d}_{5 / 2}$ and $3 \mathrm{~d}_{3 / 2}$ binding energies of all the oxidation states of Mo show a higher shift in comparison to the respective binding energy values for elemental Mo, that is, 228 and $231.1 \mathrm{eV}$ [36]. The peak pair $(230.2 \mathrm{eV}$ and $233.5 \mathrm{eV})$, which has a shift from $3 \mathrm{~d}$ doublet of elemental Mo, higher than that of Mo (IV) in $\mathrm{MoS}_{2}(1.6 \mathrm{eV})$ and lower than that for Mo (VI) in $\mathrm{MoS}_{3}(4.2 \mathrm{eV})$, can be, respectively, assigned to $3 d_{5 / 2}$ and $3 d_{3 / 2}$ (i.e., the $3 d$ doublet) binding energies of $\mathrm{Mo}(\mathrm{V})$ species in $\mathrm{Mo}_{2} \mathrm{~S}_{5}$. The $3 \mathrm{~d}$ doublet binding energies at 232.6 and $235.6 \mathrm{eV}$ in Figure 2(a) may appear due to Mo (VI) species in $\mathrm{MoS}_{3}$. However, the higher energy shift of this peak pair from that of elemental Mo than the expected value of $4.2 \mathrm{eV}$ and close proximity of the binding energies of the respective $3 \mathrm{~d}$ doublets (i.e., $3 \mathrm{~d}_{5 / 2}$ and $3 \mathrm{~d}_{3 / 2}$ ) of $\mathrm{MoS}_{3}$ and $\mathrm{MoO}_{3}$ led us to believe that the XPS peak pair at 232.6 and $235.6 \mathrm{eV}$ may be partially contributed by $3 \mathrm{~d}$ doublet for the Mo (VI) species in $\mathrm{MoO}_{3}$. This trace amount of $\mathrm{MoO}_{3}$ may be formed during the handling of the sample in ambient atmosphere. The lone peak at $237.1 \mathrm{eV}$ matches well with the respective $3 d_{3 / 2}$ binding energy of Mo (VI) species in $\mathrm{H}_{2} \mathrm{MoS}_{4}$ [35], whereas its $3 \mathrm{~d}_{5 / 2}$ counterpart of $3 \mathrm{~d}$ doublet, with binding energy at $233.8 \mathrm{eV}$, may have merged with the broad peak at $233.5 \mathrm{eV}$. The insoluble compound, $\mathrm{H}_{2} \mathrm{MoS}_{4}$, which may be resulted from one of the acidification subreactions, eventually produces $\mathrm{MoS}_{3}$ with liberation of $\mathrm{H}_{2} \mathrm{~S}$ on heating above $190^{\circ} \mathrm{C}$.

Figure 2(b) shows the XPS spectra for $\mathrm{S}$ in the asprecipitated virgin precursors obtained after acidification of ATM solution. The figure indicates the presence of three major peaks with their maxima at $162.9,166.8$, and $168.9 \mathrm{eV}$. The broad peak at $162.9 \mathrm{eV}$ has a lower binding energy value compared to that of the S $2 \mathrm{p}$ doublet (i.e., $164.1 \mathrm{eV}$ and $165.2 \mathrm{eV}$ for $\mathrm{S} 2 \mathrm{p}_{3 / 2}$ and $\mathrm{S} 2 \mathrm{p}_{1 / 2}$, resp.) in elemental sulfur [35]. However, this value is higher than the expected XPS peak positions for $2 \mathrm{p}$ doublet for $\mathrm{S}$ in $\mathrm{MoS}_{2}$ (i.e., $161.7 \mathrm{eV}$ and $162.7 \mathrm{eV}$ for $\mathrm{S} 2 \mathrm{p}_{3 / 2}$ and $\mathrm{S} 2 \mathrm{p}_{1 / 2}$, resp.). In consistency with the previous literature, the peak at $162.9 \mathrm{eV}$ is thus assigned to the binding energy of S $2 p$ in $\mathrm{MoS}_{3}$ [37]. On the other hand, the XPS peaks of $S$ located at around 166.8 and $168.9 \mathrm{eV}$ show higher binding energy values compared to that of $S$ in zero oxidation state. These peaks possibly appeared due to the presence of bisulfite (with $S$ in +4 oxidation state) and bisulfate (with $S$ in +6 oxidation state) residue in the precipitate. The bisulfite and bisulfate ions are possibly produced from aqueous solution of sodium dithionite in presence 
of oxygen [38]. Nevertheless, it is difficult to ascertain the identity of $\mathrm{Mo}_{2} \mathrm{~S}_{5}$ and $\mathrm{H}_{2} \mathrm{MoS}_{4}$ from the XPS analysis of sulfur because of nonavailability of relevant XPS data in the literature. However, on the basis of Mo $3 \mathrm{~d}$ peak analysis, it can be predicted that the brownish black uncalcined samples, which get formed during the acidification of the intermediate ammonium tetrathiomolybdate (ATM) solution, could be a mixture of amorphous $\mathrm{MoS}_{3}, \mathrm{Mo}_{2} \mathrm{~S}_{5}$, elemental $\mathrm{S}$, and a small amount of $\mathrm{H}_{2} \mathrm{MoS}_{4}$. The plausible set of reactions (2)-(4) can be written as follows [39-41]:

$$
\begin{gathered}
\mathrm{MoS}_{4}{ }^{2-}+2 \mathrm{H}^{+} \longrightarrow \mathrm{MoS}_{3} \downarrow+\mathrm{H}_{2} \mathrm{~S} \uparrow \\
2 \mathrm{MoS}_{4}{ }^{2-}+4 \mathrm{H}^{+} \longrightarrow \mathrm{Mo}_{2} \mathrm{~S}_{5} \downarrow+2 \mathrm{H}_{2} \mathrm{~S} \uparrow+\mathrm{S} \downarrow \\
\mathrm{MoS}_{4}{ }^{2-}+2 \mathrm{H}^{+} \longrightarrow \mathrm{H}_{2} \mathrm{MoS}_{4} \longrightarrow \mathrm{MoS}_{3} \downarrow+\mathrm{H}_{2} \mathrm{~S} \uparrow
\end{gathered}
$$

The simultaneous thermogravimetric (TG), differential thermogravimetric (DTG), and differential thermal analysis (DTA) of the as-precipitated brownish black powders, shown in Figure 3, supported the XPS results. The TG curve shows an initial weight loss of $\sim 2.8 \%$ below $150^{\circ} \mathrm{C}$, possibly corresponding to the removal of adsorbed water from the sample. The temperature region between 150 and $600^{\circ} \mathrm{C}$ in the TG curve can be divided into four distinct stages corresponding to various reactions involved in the decomposition process. The weight loss of $\sim 22.7 \%$ associated with the endothermic effect in the stage-I region $\left(150-240^{\circ} \mathrm{C}\right)$ could be taken as a collective effect due to loss of occluded vapors of $\mathrm{H}_{2} \mathrm{~S}, \mathrm{HCl}$, and the by-product elemental sulfur formed due to reaction (3) along with the conversion of $\mathrm{MoS}_{3}$ to $\mathrm{Mo}_{2} \mathrm{~S}_{5}$ [42] as per the following reaction:

$$
2 \mathrm{MoS}_{3} \stackrel{190-220^{\circ} \mathrm{C}}{\longrightarrow} \mathrm{Mo}_{2} \mathrm{~S}_{5}+\mathrm{S} \uparrow
$$

The stage-II $\left(240-390^{\circ} \mathrm{C}\right)$ involves the endothermic decomposition of $\mathrm{Mo}_{2} \mathrm{~S}_{5}$ to amorphous $\mathrm{MoS}_{2}$ and an additional exothermic effect [41] for the transformation $\mathrm{MoS}_{2}$ (amorphous) $\rightarrow \mathrm{MoS}_{2}$ (crystalline) in the sample. As a result, the overall thermal effect in DTA curve for stage-II is a small exothermic, which may be superimposed on a small endothermic peak. The weight loss ( 9\%) in the TG curve, in the corresponding region, matches well with the expected loss of sulfur during the conversion as follows:

$$
\begin{aligned}
\mathrm{Mo}_{2} \mathrm{~S}_{5} & \stackrel{\Delta}{\longrightarrow} \mathrm{S} \uparrow+\mathrm{MoS}_{2} \text { (amorphous) } \\
& \longrightarrow \mathrm{MoS}_{2} \text { (Crystalline) }
\end{aligned}
$$

The stage-III $\left(390-430^{\circ} \mathrm{C}\right)$ and IV $\left(430-600^{\circ} \mathrm{C}\right)$, exothermic and endothermic effects, respectively, represent the oxidation of $\mathrm{MoS}_{2}$ to $\mathrm{MoO}_{2}$ and $\mathrm{MoO}_{2}$ to $\mathrm{Mo}_{2} \mathrm{O}_{3}$, respectively [42]. The formation of $\mathrm{MoO}_{2}$ may occur due to the oxygen impurities present in argon (carrier gas for the instrument) and subsequent conversion to $\mathrm{Mo}_{2} \mathrm{O}_{3}$ at higher temperature due to local deficiency of oxygen.

Finally, the degree of crystallinity of the dried as-precipitated precursor powders was studied by X-ray diffraction (XRD), which shows a broad and diffused diffraction spectrum (Figure 4) indicating the sample to be predominantly

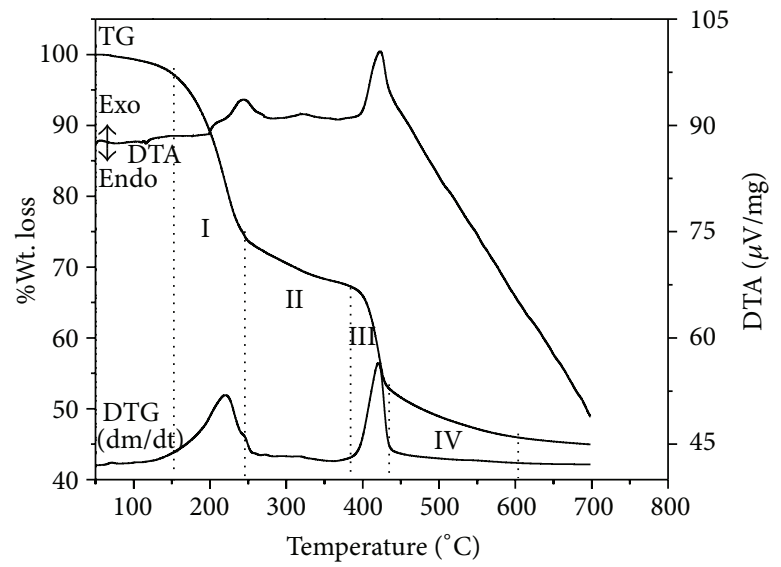

FIgURE 3: Thermograms for the decomposition of the asprecipitated precursor sample.

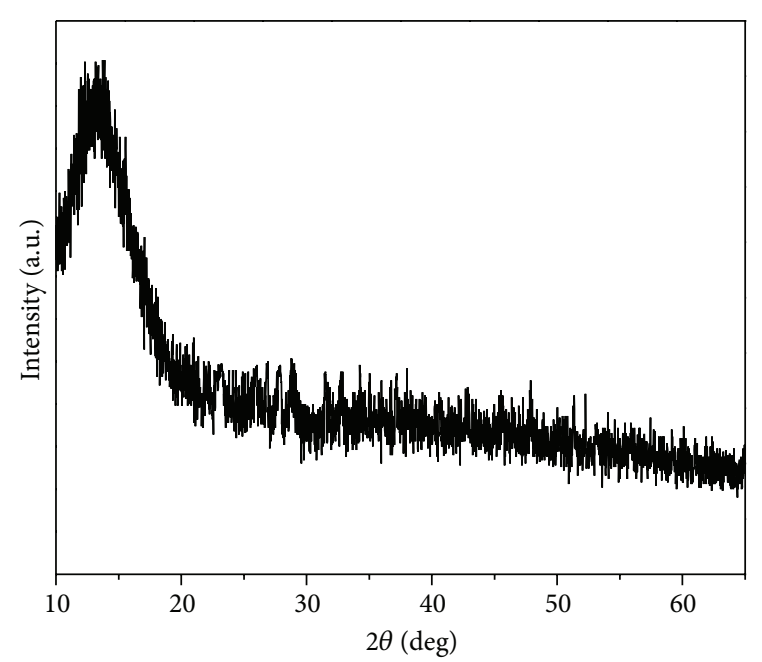

FIGURE 4: XRD pattern of the as-precipitated precursor powders.

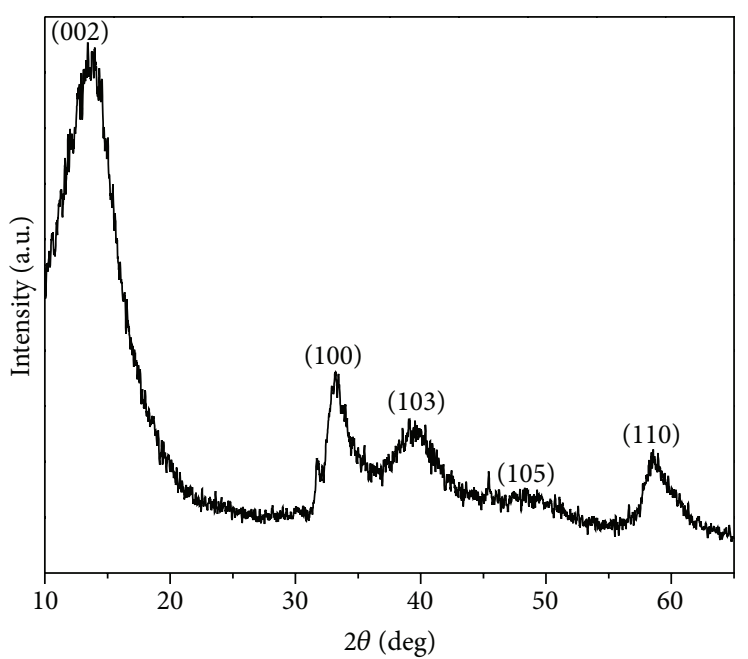

FIGURE 5: XRD pattern of the $\mathrm{MoS}_{2}$ sample after calcination at $400^{\circ} \mathrm{C}$ for $2 \mathrm{~h}$. 


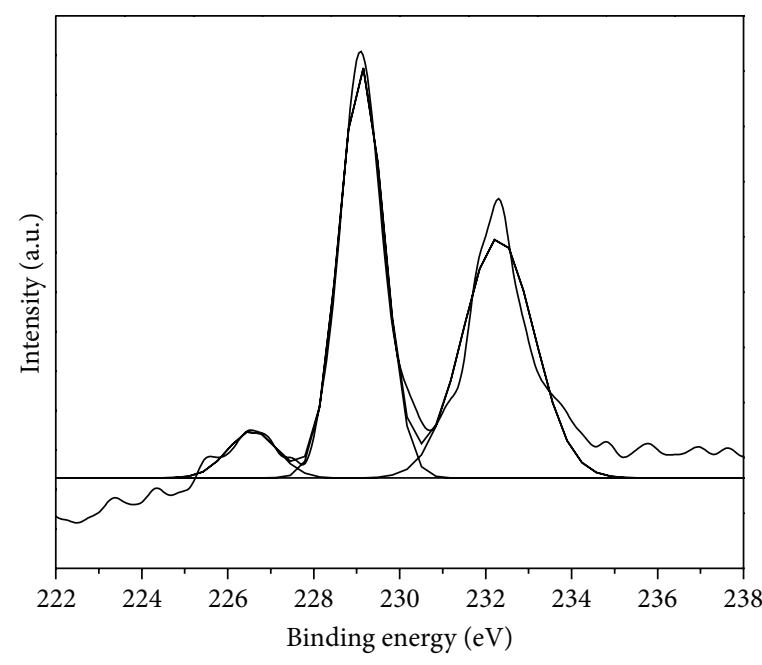

(a)

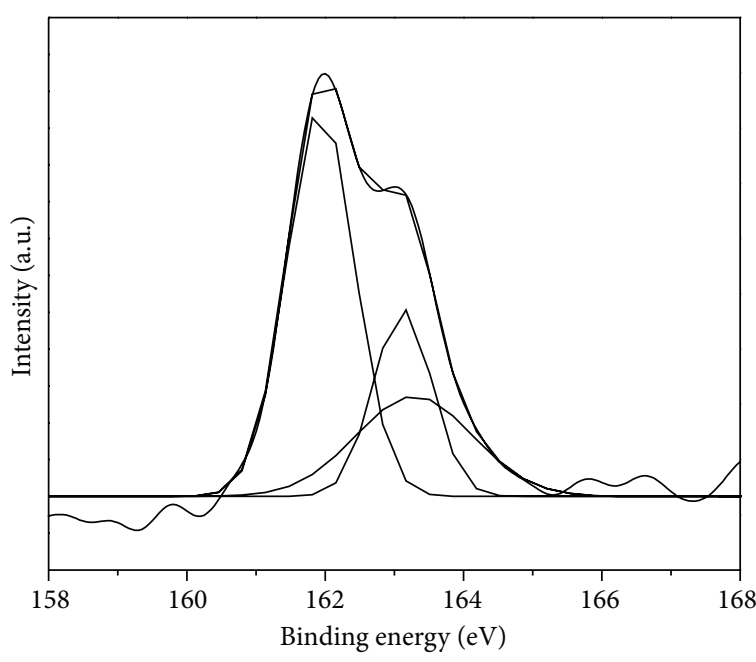

(b)

FIGURE 6: XPS spectra, before and after curve peak fitting, (a) for Mo and (b) for S in $\mathrm{MoS}_{2}$ sample, obtained after calcination at $400^{\circ} \mathrm{C}$ for $2 \mathrm{~h}$.

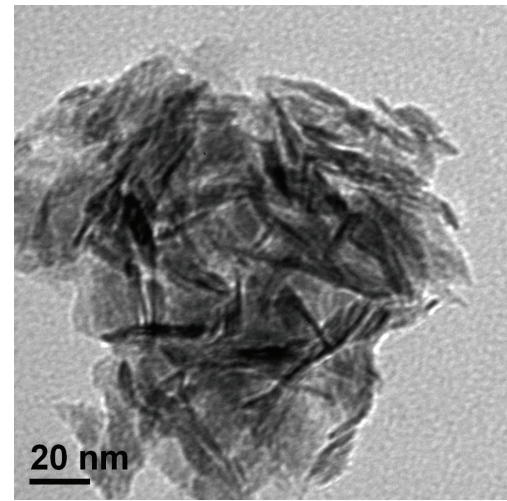

(a)

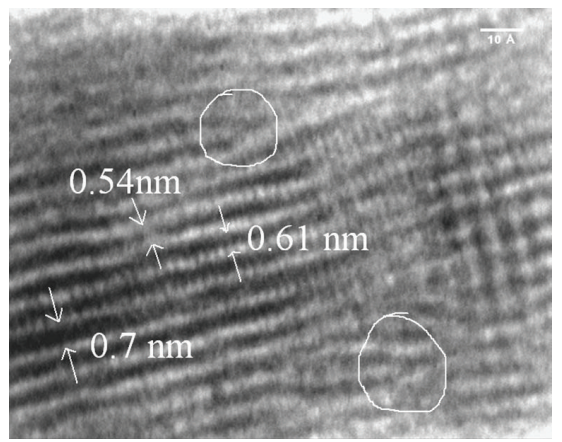

(c)

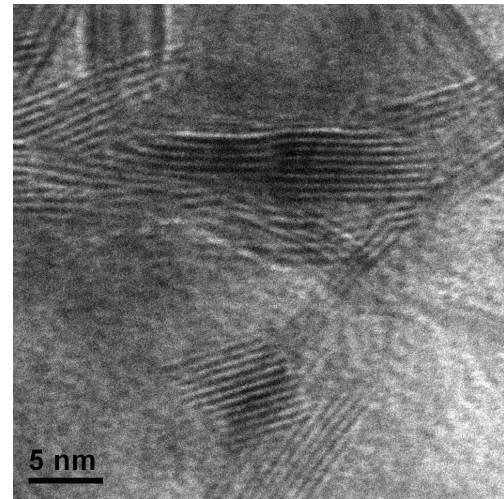

(b)

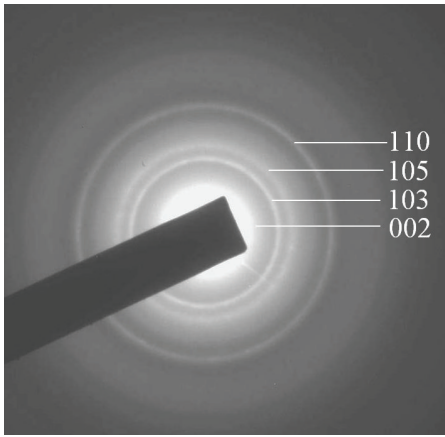

(d)

FIgURE 7: Morphological analysis of the as-obtained $\mathrm{MoS}_{2}$ product obtained after calcination at $400^{\circ} \mathrm{C}$ for $2 \mathrm{~h}$; (a) low-resolution image; (b), (c) high resolution images showing clear view of lattice fringes; (d) electron diffraction pattern of a selected area.

amorphous. The solitary peak centered at $\sim 2 \theta=13.4^{\circ}$ may be due to some amount of crystalline materials present in the sample. Of the sulfide compounds of molybdenum, $\mathrm{MoS}_{3}$ are reported to be amorphous [12, 43]. However, $\mathrm{Mo}_{2} \mathrm{~S}_{5}$, whose crystallinity nature is unknown given to the unavailability of any information in JCPDS database, may be responsible for the broad peak in Figure 4.
3.2. Analysis of the Calcined Sample. XRD pattern of the sample, obtained on calcinations of the as-precipitated powders at $400^{\circ} \mathrm{C}$ in argon atmosphere for $2 \mathrm{~h}$, shows broad but distinct XRD peaks (Figure 5). All the XRD peaks are indexed to the respective $d_{\mathrm{hkl}}$ values of the hexagonal cell of bulk $\mathrm{MoS}_{2}$ with lattice parameters $a=3.159 \AA$ and $c=12.162 \AA$ (according to JCPDS Card no. 37-1492). The $\mathrm{d}_{002}$ line for 


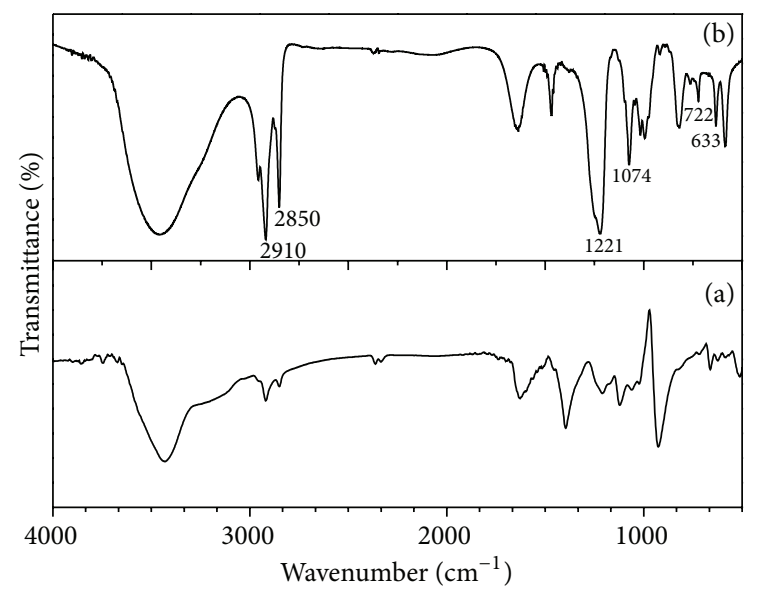

FIGURE 8: FTIR spectra of (a) the as-precipitated virgin precursor powders and (b) pure SDS.

the calcined powders is observed at $2 \theta=13.70^{\circ}$, which indicates a shift towards lower angle with respect to bulk $2 \mathrm{H}-\mathrm{MoS}_{2}$. The observed shift may be attributed to lattice expansion of $\sim 6.2 \%$ along $c$-axis due to induction of crystal defects or strains owing to the curvature of the layers [30]. This prediction is substantiated by larger $c a$. " $c$ " value of the sample ( $a=3.105 \AA$ and $c=12.911 \AA)$ compared to that reported for $2 \mathrm{H}-\mathrm{MoS}_{2}$. The diffraction pattern is comparable with the scan reported by Wildervanck and Jellinek for $\mathrm{MoS}_{2}$ prepared through the decomposition of $\mathrm{MoS}_{3}$ [12]. The average crystallite size is found to be about $33 \AA$ in $c$-direction (corresponding to approximately six $\mathrm{MoS}_{2}$ layers) and $78 \AA$ in $a$-direction. The calculations of dimensions and number of layers have been carried out in the standard manner [44] by using full width at half maximum (FWHM) of the welldefined diffraction peaks. Furthermore, the broadening of the $\mathrm{d}_{\mathrm{hkl}}$ lines gives an indication of the formation of poorly crystalline $\mathrm{MoS}_{2}$ powders.

Finally, the purity and composition of the calcined powders were analyzed by XPS. The peak pair (229.1 and $232.3 \mathrm{eV}$ ) in Figure 6(a) represents the $3 \mathrm{~d}$ doublet (i.e., $3 \mathrm{~d}_{5 / 2}$ and $3 \mathrm{~d}_{3 / 2}$, resp.) of the Mo (IV) species in $\mathrm{MoS}_{2}$, while the peak centered at $226.6 \mathrm{eV}$ can be assigned to $\mathrm{S} 2 \mathrm{~s}$ binding energy in $\mathrm{MoS}_{2}$. Figure 6(b) shows two peaks centered at 161.9 and $163.1 \mathrm{eV}$ corresponding to the $\mathrm{S} 2 \mathrm{p}$ doublet, that is, $2 \mathrm{p}_{3 / 2}$ and $2 \mathrm{p}_{1 / 2}$, respectively in $\mathrm{MoS}_{2}$ [35]. The small peak of insignificant intensities beyond $163.1 \mathrm{eV}$ may be attributed to some impurities associated with sulfur. Thus, the XPS studies indicate the formation of pure $\mathrm{MoS}_{2}$ through heat treatment of the precursor precipitate, obtained on acidification of ATM solution.

The detailed microstructure of the calcined $\mathrm{MoS}_{2}$ sample is analyzed by transmission electron microscopy. Lowresolution transmission electron micrograph (TEM) of the sample (Figure 7(a)) indicated the formation of typical lamellar structures of $\mathrm{MoS}_{2}$ analogous to that observed by Chianelli et al. [45], who termed them as rag-like structures. Peng et al. also reported similar type of rag structures, which were synthesized under drastic conditions of hydrothermal reaction [24]. At higher magnification, these structures (Figure 7(b)) reveal the presence of different number of lattices ranging from 3 to 11. The low stacking and random orientation of the lattices, characteristics of rag-like structures, are also supported by the broad XRD peaks (Figure 5). At still higher resolution, the image (Figure $7(\mathrm{c})$ ) indicates the existence of edge dislocations (in the encircled domains of the image) in the microstructure of the sample. This type of defects generally induced nonuniformity in $\mathrm{d}$-spacing between the lattices [46], which is justified by the measured fringe widths, that is, $0.54,0.61$, and $0.7 \mathrm{~nm}$, at different location of the image. This observation further demonstrates the formation of highly folded and disorder stacking character of rag-like structures [12]. However, the average width of the lattice fringes measured from the image is found to be $\sim 0.62 \mathrm{~nm}$, which is in close agreement with the characteristic $\mathrm{d}_{002}$ plane of the $2 \mathrm{H}-\mathrm{MoS}_{2}$ crystal. The selected area electron diffraction (SAED) patterns of the sample (Figure 7(d)) show diffused diffraction rings, which are indexed by matching the d-values of the $\mathrm{MoS}_{2}$ crystal in the JCPDS card 37-1492 with those calculated from measurement of the ring radii. The observed diffraction rings can be attributed to coherent diffraction by aggregate of partially crystalline nanoparticles.

Finally, the hydrodynamic size of synthesized $\mathrm{MoS}_{2}$ powders was measured, which is found to be around $299.3 \mathrm{~nm}$. Since the measured size for the particles is higher than that observed from TEM image, it can be indicated that there is presence of aggregation in the sample [47].

Based on the previous literature, it has been proposed that the formation of the poorly crystalline rag structures of $\mathrm{MoS}_{2}$ may be due to the presence of some amount of SDS residue in the precipitated precursor powders, which is evident from its FTIR spectra (Figure 8(a)). The appearance of typical infrared peaks at 2919 and $2850 \mathrm{~cm}^{-1}$ (asymmetric and symmetric $\mathrm{CH}_{2}$ vibration), $1221 \mathrm{~cm}^{-1}$ (C-C skeletal vibration), 1074 and $633 \mathrm{~cm}^{-1}\left(\mathrm{SO}_{4}{ }^{2-}\right.$ ), and $722 \mathrm{~cm}^{-1}$ (C-O stretching vibration) gives enough indication of the existence of SDS in the sample [48]. This is also confirmed by comparing the observed FTIR peaks with those obtained from pure SDS (Figure 8(b)). According to the previous reports, the precipitates, obtained through low-temperature reactions in the presence of long chain surfactants, such as cetyltrimethylammonium bromide (CTAB) or polyethylene glycol (PEG), were found to be contaminated with surfactants even after extensive washing $[22,30]$. These adsorbed surfactants were believed to be decomposed under heat treatment, resulting in the abnormal expansion of interlayer gaps. Drawing similarity with the report, it can thus be predicted that the thermal decomposition of the carbonaceous compound (i.e., SDS) adsorbed on the precursor precipitate obtained through the present preparation procedure prevents the regular stacking of the layers of molybdenum sulfide and induces faulted stacking in the structures of the synthesized $\mathrm{MoS}_{2}$.

Further verification of the role of SDS in the formation of poorly crystalline $\mathrm{MoS}_{2}$ powders with highly folded and disorder stacking layered structure has been performed by 


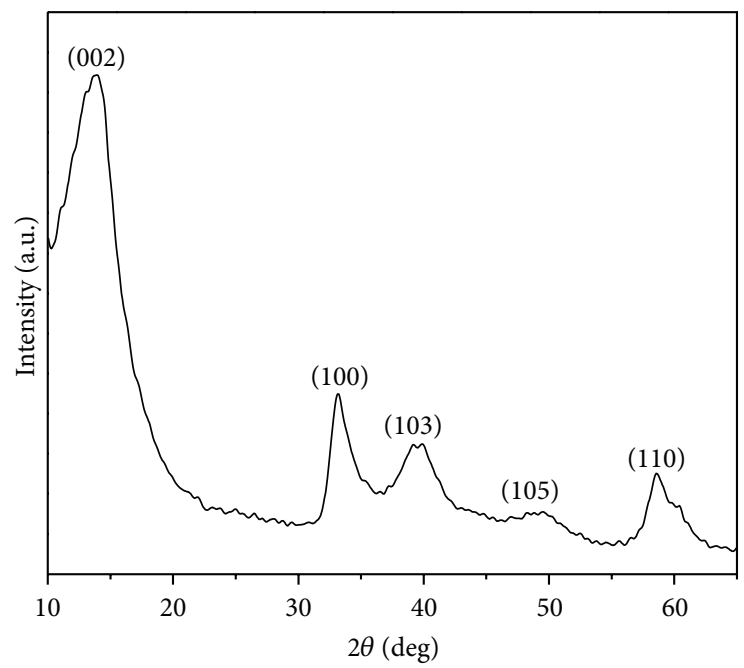

(a)

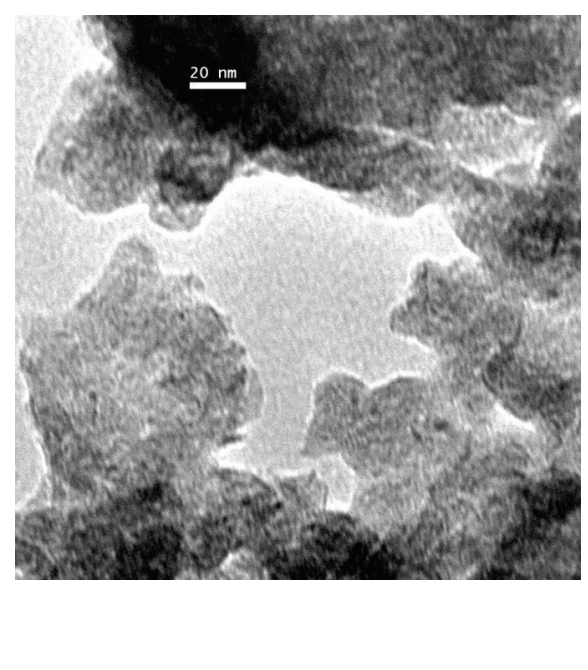

(b)

FIgURE 9: (a) XRD pattern and (b) TEM image of $\mathrm{MoS}_{2}$ sample obtained on calcination (at $400^{\circ} \mathrm{C}$ for $2 \mathrm{~h}$ ) of the precipitate prepared in absence of SDS.

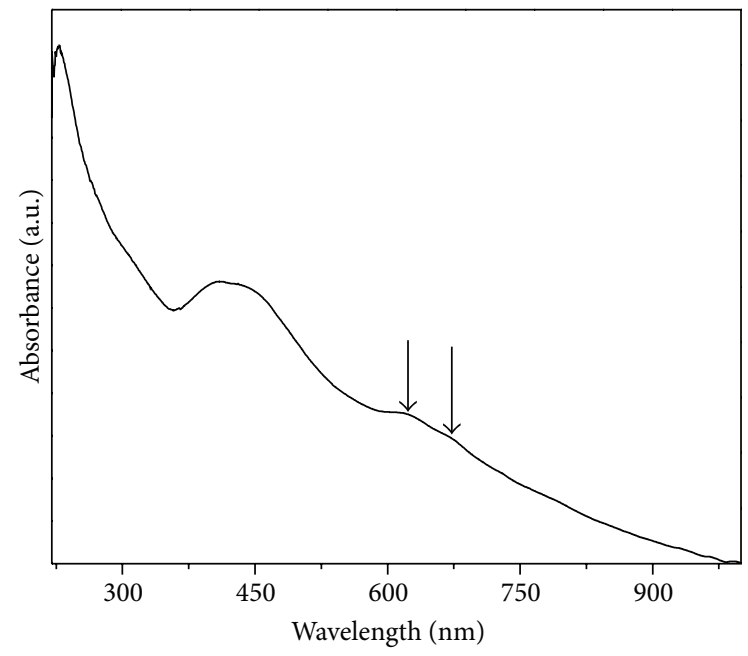

Figure 10: Optical absorption spectrum of the as-obtained $\mathrm{MoS}_{2}$ sample.

carrying out the XRD and microscopy analysis of the $\mathrm{MoS}_{2}$ sample obtained in the absence of SDS (Figure 9). The XRD pattern in Figure 9(a) displays X-ray diffraction pattern similar to that shown in Figure 5. However, the $2 \theta$ values for the (002) diffraction peak position for $\mathrm{MoS}_{2}$ samples prepared in absence of SDS (Figure 9(a)) and in presence of SDS (Figure 5) are found to be at $2 \theta \approx 14.0$ and 13.4, respectively, compared to that for bulk $2 \mathrm{H}-\mathrm{MoS}_{2}\left(2 \theta \approx 14.40^{\circ}\right)$ (according to standard data in JCPDS Card no. 37-1492). This relatively higher downward shift of the (002) peak in case of sample prepared in presence of SDS indicates the larger lattice expansion along $c$-axis, which can be ascribed to the folding and randomness in the stacking of the $\mathrm{MoS}_{2}$ layers
[30]. This finding is also supported by the TEM images of the samples. The TEM image of the $\mathrm{MoS}_{2}$ sample obtained in absence of SDS indicates the formation of agglomerations of some irregularly shaped coarse particles in contrast to that represented in Figure 7 (for $\mathrm{MoS}_{2}$ sample obtained in the presence of SDS).

3.3. Study of the Properties of the Synthesized $\mathrm{MoS}_{2}$ Sample. In order to study the optical property of the calcined powders, UV-visible absorption was taken at room temperature after dispersion in ethanol. The spectra in Figure 10 depict two weak bands centered at $\sim 675$ and $617 \mathrm{~nm}$ (marked by arrows), and a strong and very broad band with the maxima centered at $\sim 400 \mathrm{~nm}$. The first two peaks correspond to exciton A and $\mathrm{B}$ of $\mathrm{MoS}_{2}$, respectively. These exciton energy values are found to be red shifted in comparison to the respective exciton energy values assigned to the bulk $2 \mathrm{H}-\mathrm{MoS}_{2}$ (654.3 and $593.3 \mathrm{~nm}$ ) but are comparable to the respective values for nested IF-like structures (667 and $616.3 \mathrm{~nm}$ ) at $175 \mathrm{~K}$ [49]. Furthermore, the observed UV-visible spectral pattern is found similar to that reported by Liao et al. [50] for $\mathrm{MoS}_{2}$ fibers synthesized through a low-temperature soft chemical route. It can thus be inferred that the curved nanostructures of the synthesized sample may be responsible for the observed optical spectrum of the synthesized $\mathrm{MoS}_{2}$ sample.

For studying the semiconducting behavior of the prepared $\mathrm{MoS}_{2}$ samples, two pellets were prepared by pressing $\mathrm{MoS}_{2}$ powders. One of the pellets was heated at $400^{\circ} \mathrm{C}$ for $4 \mathrm{~h}$ in argon atmosphere before carrying out the electrical measurement. The plots of $\log$ of conductivity $(\log \sigma)$ versus inverse of temperature $(1 / T)$ at different frequencies (such as $100,200,500$, and $1000 \mathrm{kHz}$ ) are shown in Figures 11(a) and 11(b) for the $\mathrm{MoS}_{2}$ pellets, before and after heat treatment, respectively. Both of the samples exhibit typical 


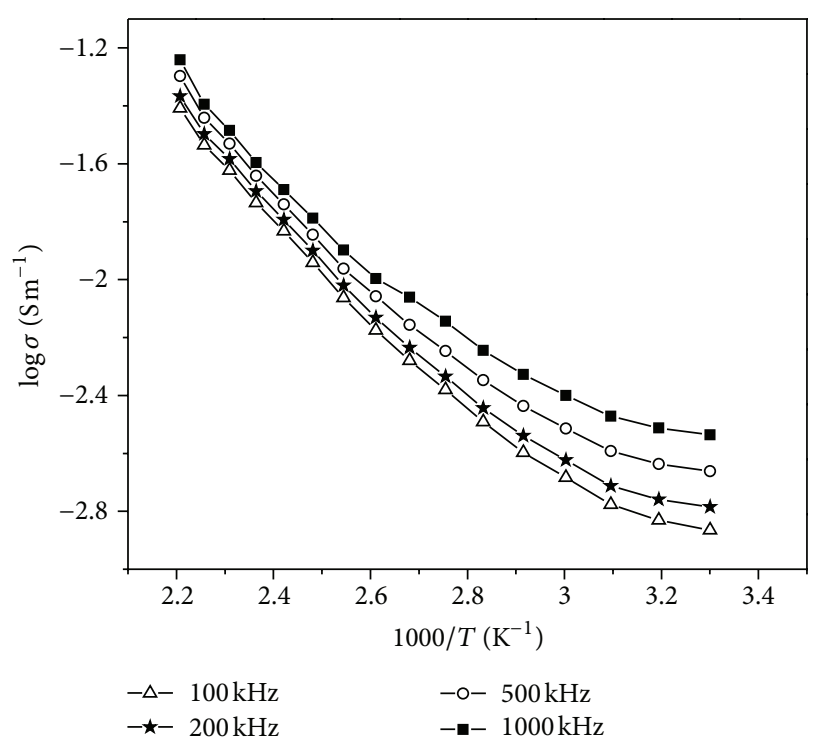

(a)

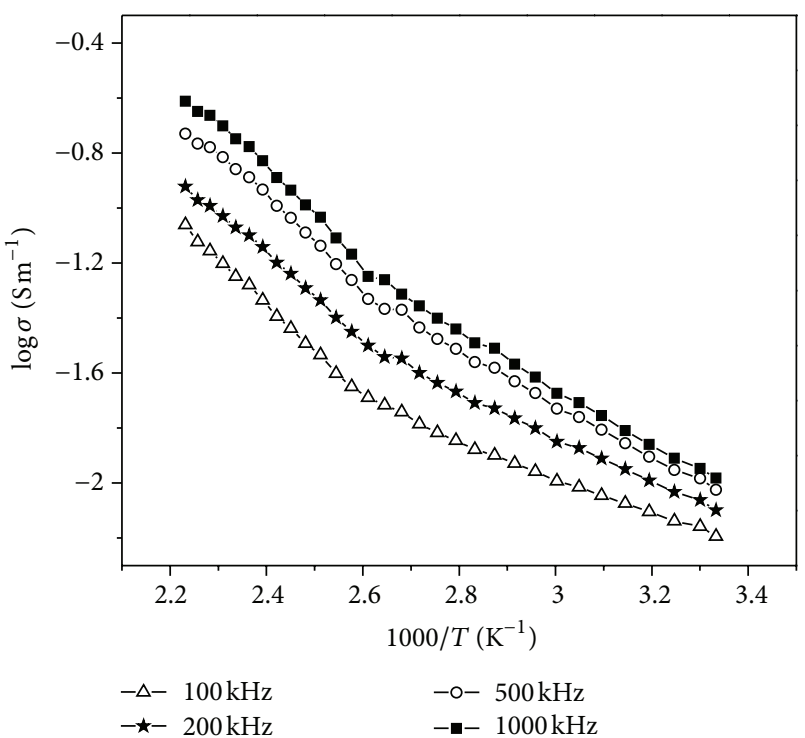

(b)

FIGURE 11: Variation of conductivity with temperature at different frequencies for pressed pellets of $\mathrm{MoS}_{2}$; (a) before heat treatment and (b) after heat treatment.

semiconductor behaviors, that is, increase in the electrical conductivity with rise in temperature. In the low frequency range (below $1 \mathrm{kHz}$ ), the electrical conductivity for both heattreated and virgin $\mathrm{MoS}_{2}$ pellets is found to be frequency independent and comparable to the DC conductivity values. The conductivity (in both, heat-treated and virgin pellets) is, however, observed to increase beyond the frequency range of $1 \mathrm{kHz}$. The frequency dependence of conductivity can be given by the following equation [51]:

$$
\begin{aligned}
\sigma & =\sigma_{\mathrm{dc}}+\sigma_{\mathrm{ac}} \\
& =\sigma_{\mathrm{dc}}+A \omega^{n},
\end{aligned}
$$

where $A$ and $n$ are materials parameters $(0<n<1), \sigma_{\mathrm{dc}}$ is "DC conductivity" or frequency independent part, $\sigma_{\mathrm{ac}}$ and $\omega$ are AC conductivity and angular frequency, respectively.

Further, from Figure 11, the plots of $\log \sigma$ versus $(1 / T)$ are observed to undergo a change in slope beyond $373 \mathrm{~K}$ for both the samples. Relatively less significant rise in electrical conductivities of the samples at temperatures below $373 \mathrm{~K}$ is probably due to $\sigma_{\mathrm{ac}}$ part being the major contributor to the total measured conductivity for the sample, owing to the fact that $\mathrm{AC}$ conductivity of semiconductors is only weakly dependent on temperature compared to $\sigma_{\mathrm{dc}}$ [52]. At intermediate and higher temperature range, the $\sigma_{\mathrm{dc}}$ part possibly contributes significantly, and thus the samples shows a noticeable rise in conductivity with temperature. Similar nonlinear dependence of log conductivity on $(1 / T)$ for $\mathrm{MoS}_{2}$ has been reported by Sienicki [53], who showed that $\log \sigma$ for $\mathrm{MoS}_{2}$ varied exponentially with reciprocal of temperature $(1 / T)$ at higher temperatures.

In addition, the conductivity measured at room temperature $(303 \mathrm{~K})$ for the heat-treated pellet $\left(1.13 \times 10^{-2} \mathrm{~S} \mathrm{~m}^{-1}\right)$ is found to be 16 times higher than that of the virgin pellet $\left(6.88 \times 10^{-4} \mathrm{~S} \mathrm{~m}^{-1}\right)$. This significant improvement in $\sigma_{\mathrm{ac}}$ may be due to the densification of the heat-treated pellet through grain growth at higher temperature. The activation energies $\left(E_{a}\right)$ of the samples were also calculated from the slope of the $\log \sigma$ versus $1 / T$ curve at a frequency of $1000 \mathrm{kHz}$ using Arrhenius equation. Contrary to the trend of $\sigma$, the $E_{a}$ values for heat-treated pellet $(0.259 \mathrm{eV})$ and virgin pellet $(0.258 \mathrm{eV})$ were found to be comparable.

Finally, the BET surface area of the calcined sample has been determined by using BET surface area measurement instrument, which is found to be $35 \mathrm{~m}^{2} / \mathrm{g}$. In spite of the low surface area value, based on some previous studies [10, 54, 55] and the morphological analysis, the synthesized $\mathrm{MoS}_{2}$ sample in the present technique, however, may be predicted to exhibit better catalytic activity. According to the studies by Tanaka and Okuhara [54], the difference in catalytic activity of layered transition metal chalcogenides such as $\mathrm{MoS}_{2}$ is not accounted for by BET surface area or pore structure but depends on the morphology, in particular on the ratio of basal and edge planes. This fact was also vindicated by the experimental observation by Iwata et al. [10] and Uzcanga et al. [55]. For example, Iwata et al. [10] claimed that the poorly crystalline $\mathrm{MoS}_{2}$ sample with highly bent multilayered structure provides larger number of catalytically active sites than the well-crystallized sample in spite of having surface area as low as $10 \mathrm{~m}^{2} / \mathrm{g}$. This improvement in catalytic property was ascribed to the high content of edges and defects induced in the $\mathrm{MoS}_{2}$ layers of the synthesized sample. Uzcanga et al. [55] also anticipated enhanced catalytic performance for the sonochemically prepared $\mathrm{MoS}_{2}$ powders compared to that of the conventionally prepared sample, even though the former sample displayed lower surface area. 


\section{Conclusions}

We have reported a simple aqueous solution-based precipitation route for the preparation of rag-like structures of $\mathrm{MoS}_{2}$ using some easily available laboratory reagents. As all of the reagents used are fairly soluble in water, there is less possibility of having impurities in the final products. The acidification of ATM solution with concentrated $\mathrm{HCl}$ resulted in the formation of a mixture of amorphous $\mathrm{MoS}_{3}$ and $\mathrm{Mo}_{2} \mathrm{~S}_{5}$ with small amount of elemental sulfur and $\mathrm{H}_{2} \mathrm{MoS}_{4}$, as evident from XPS and thermal analysis. However, XRD patterns indicated the formation of pure but poorly crystalline $\mathrm{MoS}_{2}$ phase on calcining the as-precipitated samples at $400^{\circ} \mathrm{C}$ for $2 \mathrm{~h}$ in argon atmosphere. The calcined powders were found to be composed of significantly folded and randomly oriented S-Mo-S layers of $\mathrm{MoS}_{2}$ as visible from high-resolution TEM images. This observation was supported by the red shifting of the exciton peak positions in UV-visible spectrum of solid $\mathrm{MoS}_{2}$. The unique morphologies of the prepared $\mathrm{MoS}_{2}$ sample may be applied as a potential catalyst for hydrodesulfurization reactions. The electrical conductivity of $\mathrm{MoS}_{2}$ sample was found to increase on annealing.

\section{Acknowledgments}

The authors acknowledge the Department of Science and Technology, Government of India, for the financial support to carry out this work. The authors also acknowledge their sincere thanks to Professor P. V. Satyam and Professor Shikha Varma of Institute of Physics, Bhubaneswar, for sample characterization by HRTEM and XPS, respectively.

\section{References}

[1] L. Rapoport, N. Fleischer, and R. Tenne, "Applications of $\mathrm{WS}_{2}$ $\left(\mathrm{MoS}_{2}\right)$ inorganic nanotubes and fullerene-like nanoparticles for solid lubrication and for structural nanocomposites," Journal of Materials Chemistry, vol. 15, no. 18, pp. 1782-1788, 2005.

[2] M. H. Cho, J. Ju, S. J. Kim, and H. Jang, “Tribological properties of solid lubricants (graphite, $\mathrm{Sb}_{2} \mathrm{~S}_{3}, \mathrm{MoS}_{2}$ ) for automotive brake friction materials," Wear, vol. 260, no. 7-8, pp. 855-860, 2006.

[3] N. Imanishi, K. Kanamura, and Z. I. Takehara, "Synthesis of $\mathrm{MoS}_{2}$ thin film by chemical vapor deposition method and discharge characteristics as a cathode of the lithium secondary battery," Journal of the Electrochemical Society, vol. 139, no. 8, pp. 2082-2087, 1992.

[4] E. Gourmelon, O. Lignier, H. Hadouda et al., " $\mathrm{MS}_{2}(\mathrm{M}=\mathrm{W}, \mathrm{Mo})$ photosensitive thin films for solar cells," Solar Energy Materials and Solar Cells, vol. 46, no. 2, pp. 115-121, 1997.

[5] W. M. R. Divigalpitiya, R. F. Frindt, and S. R. Morrison, "Inclusion systems of organic molecules in restacked singlelayer molybdenum disulfide," Science, vol. 246, no. 4928, pp. 369-371, 1989.

[6] A. Zak, Y. Feldman, V. Lyakhovitskaya et al., "Alkali metal intercalation of $\mathrm{MS}_{2}(\mathrm{M}=\mathrm{W}, \mathrm{Mo})$ fullerene-like nanoparticles and bulk $(2 \mathrm{H})$ powders," Journal of the American Chemical Society, vol. 124, no. 17, pp. 4747-4758, 2002.

[7] J. Chen, S. L. Li, Q. Xu, and K. Tanaka, "Synthesis of openended $\mathrm{MoS}_{2}$ nanotubes and the application as the catalyst of methanation," Chemical Communications, no. 16, pp. 1722-1723, 2002.

[8] E. Devers, P. Afanasiev, B. Jouguet, and M. Vrinat, "Hydrothermal syntheses and catalytic properties of dispersed molybdenum sulfides," Catalysis Letters, vol. 82, no. 1-2, pp. 13-17, 2002.

[9] B. Yoosuk, J. H. Kim, C. Song, C. Ngamcharussrivichai, and P. Prasassarakich, "Highly active $\mathrm{MoS}_{2}, \mathrm{CoMoS}_{2}$ and $\mathrm{NiMoS}_{2}$ unsupported catalysts prepared by hydrothermal synthesis for hydrodesulfurization of 4,6-dimethyldibenzothiophene," Catalysis Today, vol. 130, no. 1, pp. 14-23, 2008.

[10] Y. Iwata, K. Sato, T. Yoneda et al., "Catalytic functionality of unsupported molybdenum sulfide catalysts prepared with different methods," Catalysis Today, vol. 45, no. 1-4, pp. 353-359, 1998.

[11] M. Nath, A. Govindaraj, and C. N. R. Rao, "Simple synthesis of $\mathrm{MoS}_{2}$ and $\mathrm{WS}_{2}$ nanotubes," Advanced Materials, vol. 13, no. 4, pp. 283-286, 2001.

[12] J. C. Wildervanck and F. Jellinek, "Preparation and crystallinity of molybdenum and tungsten sulfides," Zeitschrift Für Anorganische und Allgemeine Chemie, vol. 328, no. 5-6, pp. 309-318, 1964.

[13] R. N. Viswanath and S. Ramasamy, "Preparation and isochronal sintering behavior of molybdenum disulfide compound," Journal of Materials Science, vol. 25, no. 12, pp. 5029-5035, 1990.

[14] Y. Feldman, G. L. Frey, M. Homyonfer et al., "Bulk synthesis of inorganic fullerene-like $\mathrm{MS}_{2}(\mathrm{M}=\mathrm{Mo}, \mathrm{W})$ from the respective trioxides and the reaction mechanism," Journal of the American Chemical Society, vol. 118, no. 23, pp. 5362-5367, 1996.

[15] Y. Feldman, E. Wasserman, D. J. Srolovitz, and R. Tenne, "Highrate, gas-phase growth of $\mathrm{MoS}_{2}$ nested inorganic fullerenes and nanotubes," Science, vol. 267, no. 5195, pp. 222-225, 1995.

[16] P. A. Parilla, A. C. Dillon, K. M. Jones et al., "The first true inorganic fullerenes?” Nature, vol. 397, article 114, 1999.

[17] M. J. Yacamán, H. López, P. Santiago, D. H. Galván, I. L. Garzón, and A. Reyes, "Studies of $\mathrm{MoS}_{2}$ structures produced by electron irradiation," Applied Physics Letters, vol. 69, no. 8, pp. 1065-1067, 1996.

[18] G. Chu, G. Bian, Y. Fu, and Z. Zhang, "Preparation and structural characterization of nano-sized amorphous powders of $\mathrm{MoS}_{2}$ by $\gamma$-irradiation method," Materials Letters, vol. 43, no. 3, pp. 81-86, 2000.

[19] M. Potoczek, K. Przybylski, and M. Rekas, "Defect structure and electrical properties of molybdenum disulphide," Journal of Physics and Chemistry of Solids, vol. 67, no. 12, pp. 2528-2535, 2006.

[20] A. J. Grant, T. M. Griffiths, G. D. Pitt, and A. D. Yoffe, "The electrical properties and the magnitude of the indirect gap in the semiconducting transition metal dichalcogenide layer crystals," Journal of Physics C, vol. 8, no. 1, article 004, pp. L17-L23, 1975.

[21] E. Benavente, M. A. Santa Ana, and G. González, "Electrical conductivity of $\mathrm{MoS}_{2}$ based organic-inorganic nanocomposites," Physica Status Solidi B, vol. 241, no. 10, pp. 2444-2447, 2004.

[22] N. Berntsen, T. Gutjahr, L. Loeffler, J. R. Gomm, R. Seshadri, and W. Tremel, "A solvothermal route to high-surface-area nanostructured $\mathrm{MoS}_{2}$," Chemistry of Materials, vol. 15, no. 23, pp. 4498-4502, 2003.

[23] Q. Li, M. Li, Z. Chen, and C. Li, "Simple solution route to uniform $\mathrm{MoS}_{2}$ particles with randomly stacked layers," Materials Research Bulletin, vol. 39, no. 7-8, pp. 981-986, 2004. 
[24] Y. Peng, Z. Meng, C. Zhong et al., "Hydrothermal synthesis of $\mathrm{MoS}_{2}$ and its pressure related crystallization," Journal of Solid State Chemistry, vol. 159, no. 1, pp. 170-173, 2001.

[25] J. H. Zhan, Z. D. Zhang, X. F. Qian, C. Wang, Y. Xie, and Y. T. Qian, "Solvothermal synthesis of nanocrystalline $\mathrm{MoS}_{2}$ from $\mathrm{MoO}_{3}$ and elemental sulfur," Journal of Solid State Chemistry, vol. 141, no. 1, pp. 270-273, 1998.

[26] M. M. Mdleleni, T. Hyeon, and K. S. Suslick, "Sonochemical synthesis of nanostructured molybdenum sulfide," Journal of the American Chemical Society, vol. 120, no. 24, pp. 6189-6190, 1998.

[27] I. Bezverkhy, P. Afanasiev, and M. Lacroix, "Aqueous preparation of highly dispersed molybdenum sulfide," Inorganic Chemistry, vol. 39, no. 24, pp. 5416-5417, 2000.

[28] P. Afanasiev, G. F. Xia, G. Berhault, B. Jouguet, and M. Lacroix, "Surfactant-assisted synthesis of highly dispersed molybdenum sulfide," Chemistry of Materials, vol. 11, no. 11, pp. 3216-3219, 1999.

[29] K. H. Hu, Y. R. Wang, X. G. Hu, and H. Z. Wo, "Preparation and characterization of ball-like $\mathrm{MoS}_{2}$ nanoparticles," Materials Science and Technology, vol. 23, no. 2, pp. 242-246, 2007.

[30] Z. Wu, D. Wang, and A. Sun, "Surfactant-assisted fabrication of $\mathrm{MoS}_{2}$ nanospheres," Journal of Materials Science, vol. 45, no. 1, pp. 182-187, 2010.

[31] P. Pramanik and S. Bhattacharya, "Deposition of molybdenum chalcogenide thin films by the chemical deposition technique and the effect of bath parameters on these thin films," Materials Research Bulletin, vol. 25, no. 1, pp. 15-23, 1990.

[32] J. W. McDonald, G. D. Friesen, L. D. Rosenhein, and W. E. Newton, "Syntheses and characterization of ammonium and tetraalkylammonium thiomolybdates and thiotungstates," Inorganica Chimica Acta, vol. 72, pp. 205-210, 1983.

[33] H. W. Hou, X. Q. Xin, and S. Shi, "Mo(W, V)-Cu(Ag)-S(Se) cluster compounds," Coordination Chemistry Reviews, vol. 153, pp. 25-56, 1996.

[34] J. Grigas, E. Talik, and V. Lazauskas, "X-ray photoelectron spectra and electron structure of $\mathrm{Bi}_{2} \mathrm{~S}_{3}$ crystals," Physica Status Solidi B, vol. 232, no. 2, pp. 220-230, 2002.

[35] H. W. Wang, P. Skeldon, and G. E. Thompson, "XPS studies of $\mathrm{MoS}_{2}$ formation from ammonium tetrathiomolybdate solutions," Surface and Coatings Technology, vol. 91, no. 3, pp. 200207, 1997.

[36] C. D. Wagner, W. M. Riggs, L. E. Davis, and J. F. Moulder, Handbook of X-Ray Photoelectron Spectroscopy, Perkin-Elmer, Minneapolis, Minn, USA, 1979.

[37] Y. Peng, Z. Meng, C. Zhong, J. Lu, Z. Yang, and Y. Qian, “Tubeand ball-like amorphous $\mathrm{MoS}_{2}$ prepared by a solvothermal method," Materials Chemistry and Physics, vol. 73, no. 2-3, pp. 327-329, 2002.

[38] C. E. Housecroft and A. G. Sharpe, Inorganic Chemistry, Pearson, Upper Saddle River, NJ, USA, 3rd edition, 2008.

[39] V. Yatirajam, U. Ahuja, and L. R. Kakkar, "Use of sulfide precipitation in separation and determination of molybdenum (V)," Talanta, vol. 23, no. 11-12, pp. 819-822, 1976.

[40] H. W. Wang, P. Skeldon, G. E. Thompson, and G. C. Wood, "Synthesis of molybdenum disulphide by acidification of ammonium tetrathiomolybdate solutions," Journal of Materials Science Letters, vol. 15, no. 6, pp. 494-496, 1996.

[41] H. W. Wang, P. Skeldon, G. E. Thompson, and G. C. Wood, "Synthesis and characterization of molybdenum disulphide formed from ammonium tetrathiomolybdate," Journal of Materials Science, vol. 32, no. 2, pp. 497-502, 1997.
[42] H. W. Wang, P. Skeldon, and G. E. Thompson, "Thermogravimetric-differential thermal analysis of the solid-state decomposition of ammonium tetrathiomolybdate during heating in argon," Journal of Materials Science, vol. 33, no. 12, pp. 3079-3083, 1998.

[43] P. Ratnasamy, L. Rodrique, and A. J. Leonard, "Structural and textural studies in molybdenum sulfide systems," Journal of Physical Chemistry, vol. 77, no. 18, pp. 2242-2245, 1973.

[44] H. P. Klug and L. E. Alexander, X-Ray Diffraction Procedures for Polycrystalline and Amorphous Materials, John Wiley \& Sons, New York, NY, USA, 1974.

[45] R. R. Chianelli, E. B. Prestridge, T. A. Pecoraro, and J. P. Deneufville, "Molybdenum disulfide in the poorly crystalline "rag" structure," Science, vol. 203, no. 4385, pp. 1105-1107, 1979.

[46] A. Plancon, "New modeling of X-ray diffraction by disordered lamellar structures, such as phyllosilicates," American Mineralogist, vol. 87, no. 11-12, pp. 1672-1677, 2002.

[47] P. Venkatesan, N. Puvvada, R. Dash et al., "The potential of celecoxib-loaded hydroxyapatite-chitosan nanocomposite for the treatment of colon cancer," Biomaterials, vol. 32, no. 15, pp. 3794-3806, 2011.

[48] J. Coates, Interpretation of Infrared Spectra, A Practical Approach, Encyclopedia of Analytical Chemistry, John Wiley \& Sons, Chichester, UK, 2000.

[49] G. L. Frey, S. Elani, M. Homyonfer, Y. Feldman, and R. Tenne, "Optical-absorption spectra of inorganic fullerenelike $\mathrm{MS}_{2}(\mathrm{M}$ = Mo, W)," Physical Review B, vol. 57, no. 11, pp. 6666-6671, 1998.

[50] H. Liao, Y. Wang, S. Zhang, and Y. T. Qian,, "A solution lowtemperature route to $\mathrm{MoS}_{2}$ fiber," Chemistry of Materials, vol. 13, no. 1, pp. 6-8, 2001.

[51] M. Siekierski, W. Wieczorek, and J. Przyluski, "AC conductivity studies of composite polymeric electrolytes," Electrochimica Acta, vol. 43, no. 10-11, pp. 1339-1342, 1998.

[52] S. R. Elliot, "AC conduction in amorphous chalcogenide and pnictide semiconductors," Advances in Physics, vol. 36, no. 2, pp. 135-217, 1987.

[53] W. Sienicki, "Statistical methods of investigations on the electrical properties of molybdenum disulphide intercalates," Materials Chemistry and Physics, vol. 72, no. 3, pp. 347-351, 2001.

[54] K. I. Tanaka and T. Okuhara, "Regulation of intermediates on sulfided nickel and molybdenum disulfide catalysts," Catalysis Reviews, vol. 15, no. 1, pp. 249-292, 1977.

[55] I. Uzcanga, I. Bezverkhyy, P. Afanasiev, C. Scott, and M. Vrinat, "Sonochemical preparation of $\mathrm{MoS}_{2}$ in aqueous solution: replication of the cavitation bubbles in an inorganic material morphology," Chemistry of Materials, vol. 17, no. 14, pp. 35753577, 2005. 

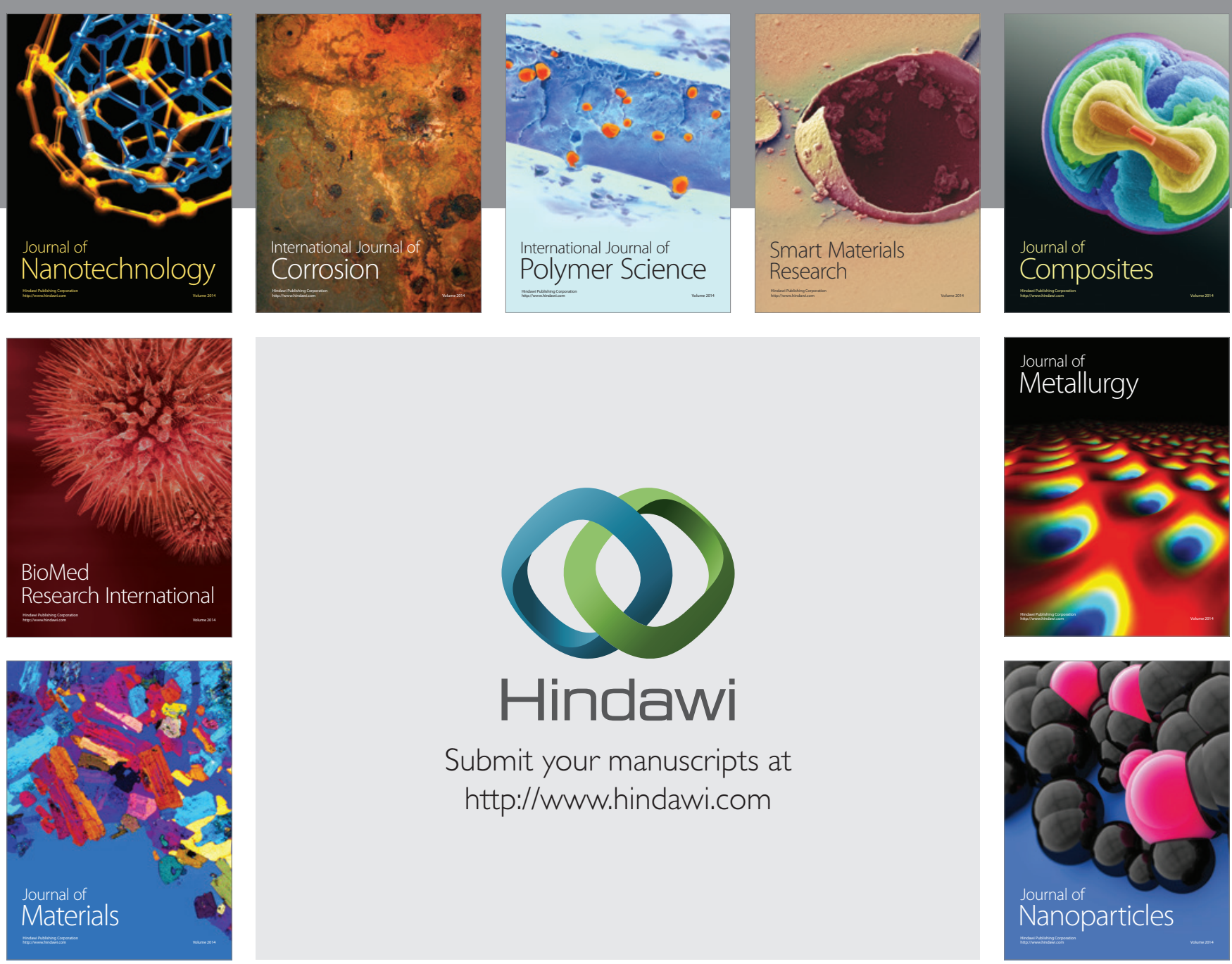

Submit your manuscripts at http://www.hindawi.com
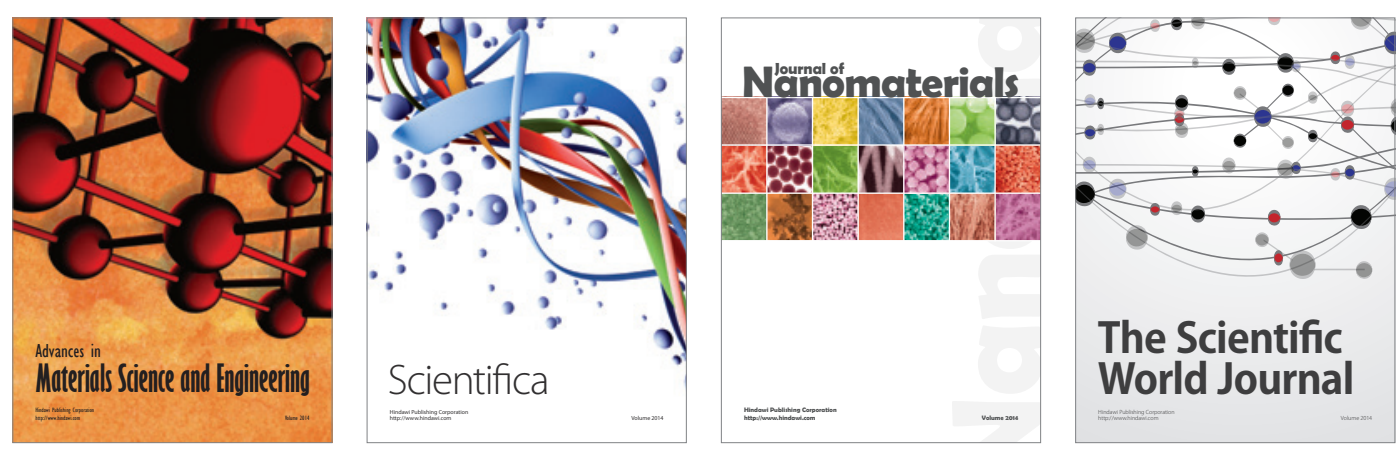

\section{The Scientific World Journal}
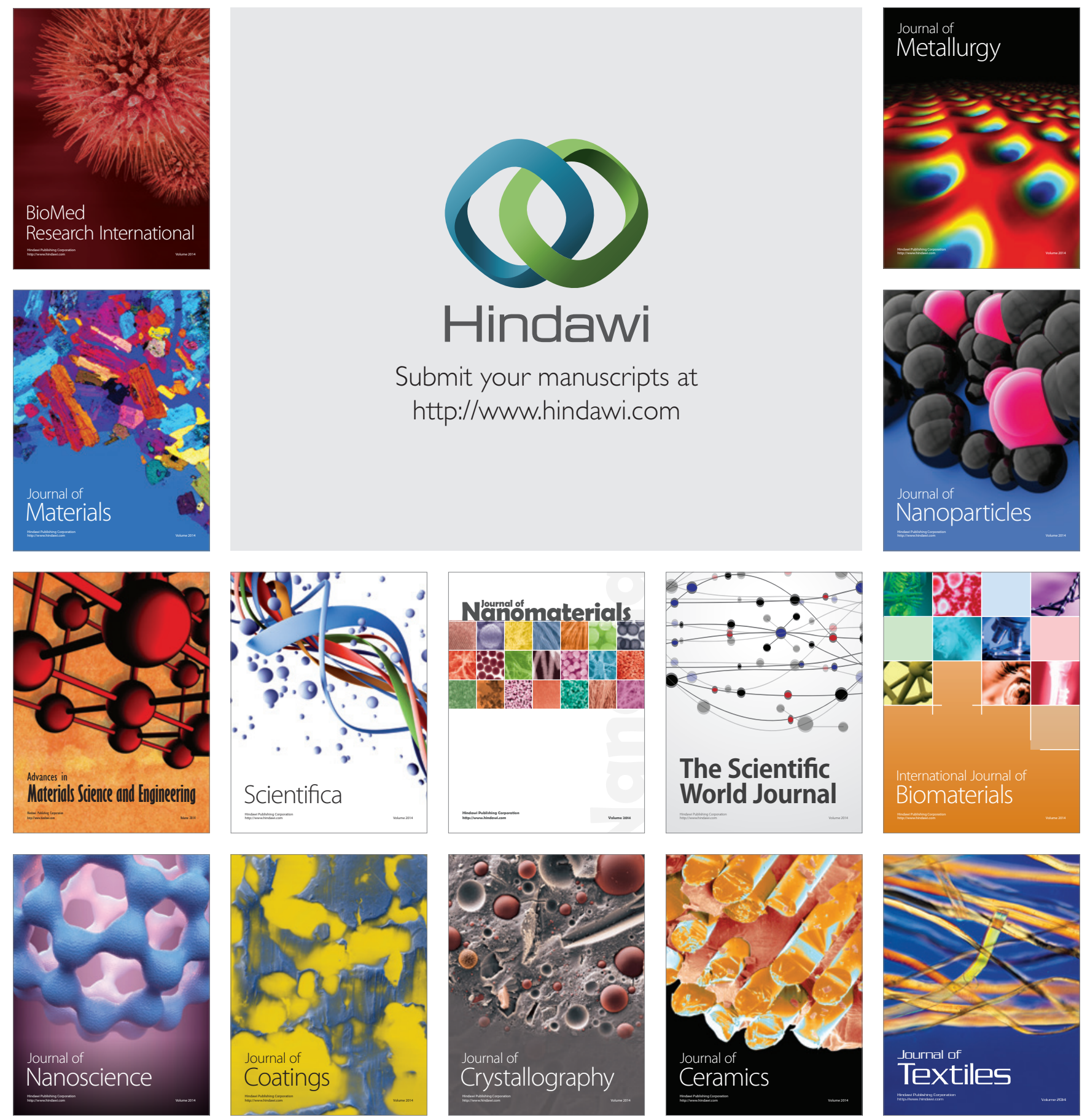